\title{
A category-mistake in the classical labour theory of value
}

\author{
IAN WRIGHT \\ The Open University
}

\begin{abstract}
The classical labour theory of value generates two well-known contradictions: Ricardo's problem of an invariable measure of value and Marx's transformation problem. I show that both contradictions derive from a category-mistake of supposing that technical costs and total costs are of the same logical type. This category-mistake is the underlying cause of the almost two hundred year history of the 'value controversy'. Once identified we can avoid the mistake, which reveals a more general labour theory of value with an invariable measure of value and without a transformation problem.
\end{abstract}

Keywords: classical political economy, labour theory of value, Ricardo, Marx, problem of an invariable measure, transformation problem

JEL Classification: B51, E11, D46

The natural prices of reproducible commodities vary with the distribution of income whereas their real costs of production, measured in labour time, do not. In consequence, labour costs cannot fully explain the structure of natural prices. This explanatory gap creates two famous problems in the classical labour theory of value: David Ricardo's problem of an invariable measure of value and Karl Marx's transformation problem. The problems imply that a labour theory of value is, at best, incomplete, or worse, logically incoherent (e.g., Seton 1957; Samuelson 1971; Lippi 1979; Steedman 1981).

Nonetheless, dissatisfaction with economic foundations based on the "shallow and superficial framework of supply and demand concepts" (Foley 2000, 2) has ensured a continued interest in the classical problems.

AUTHOR's Note: This work is the result of my current PhD studies supervised by Andrew Trigg at the Open University. Feedback from many people helped me refine the ideas that resulted in this paper. I would particularly like to express gratitude to Andrew Trigg, David Zachariah, Fernando Martins, Angelo Reati, Peter Flaschel, members of the OPE-L discussion group, the editors of this journal and the anonymous referees. 
Despite significant intellectual effort, however, the classical problems remain essentially insoluble (see Howard and King 1989, chapter 2; Howard and King 1992, chapter 14).

For "ordinary language philosophers" (Passmore 1978, 424-465), such as Gilbert Ryle (1984 [1949]) and Ludwig Wittgenstein (1953), the underlying cause of a long-lived and insoluble problem is often a hidden conceptual confusion or mistake. The problem is insoluble because the conceptual framework in which the problem is stated is itself faulty. The problem must therefore be deflated or dissolved by applying "conceptual analysis" (Sloman 1978, chapter 4).

For instance, Ryle introduced the term "category-mistake” (Ryle 1984 [1949], chapter 1) to denote the conceptual error of expecting some concept or thing to possess properties it cannot have. For example, John Doe may be a relative, friend, enemy or stranger to Richard Roe; but he cannot be any of these things to the "Average Taxpayer". So if "John Doe continues to think of the Average Taxpayer as a fellow-citizen, he will tend to think of him as an elusive an insubstantial man, a ghost who is everywhere yet nowhere" (Ryle 1984 [1949], 18).

The argument of this essay is that the contradictions of the classical labour theory of value derive from a "theoretically interesting categorymistake" (Ryle 1984 [1949], 19), specifically the mistake of supposing that classical labour-values, which measure strictly technical costs of production, are of the same logical type as natural prices, which measure social costs of production, and in consequence labour-values and prices, under appropriate equilibrium conditions, are mutually consistent. Since this supposition is mistaken, Ricardo's search for an invariable measure of value and Marx's search for a transformation between labour-values and prices attempt to discover a commensurate relationship between concepts defined by incommensurate cost accounting conventions. They therefore seek an "elusive and insubstantial man" or "ghost".

The identification of a category-mistake allows a resolution of the classical problems by "giving prominence to distinctions which our ordinary forms of language make us easily overlook" (Wittgenstein 1953, § 132). Such distinctions can then solve, or more accurately, dissolve the problems.

This essay therefore draws a new distinction, lacking in the classical labour theory, between a technical and a total measure of labour cost, where technical labour cost corresponds to the classical concept and total 
labour cost includes additional real costs of production incurred in virtue of non-technical, or social, conditions of production, such as production financed by money-capital. The more refined conceptual framework separates theoretical concerns that are conflated in the classical theory. For example, classical labour-values apply to distribution-independent questions about an economy, such as the productivity of labour over time or the quantity of "surplus labour" supplied by workers to capitalists (i.e., technical issues or questions in the theory of labour exploitation), whereas total labour-values apply to distribution-dependent questions, such as the relationship between nominal prices and the actual labour time required to produce commodities (i.e., issues in the theory of economic value). The classical problems dissolve by generalizing the classical labour theory to apply both concepts of labour cost in the appropriate contexts. In consequence, I sketch, in an initial and incomplete manner, a new theoretical object: a more general labour theory of value with an invariable measure of value and without a transformation problem.

The structure of this essay is as follows. The next three sections specify how the classical problems manifest in the simplest possible casethat of a capitalist economy in steady-state equilibrium. A section then introduces the concept of a 'total labour cost', in contradistinction to the classical concept, by applying conceptual analysis to the concept 'labourvalue'. The following three sections formally define total labour costs in the case of steady-state equilibrium. The final three sections explain how the new distinction dissolves the classical problems.

\section{THE DEFINITION OF 'LABOUR-VALUE'}

Since the seminal contribution of Ladislaus von Bortkiewicz (1975 [1907]), the transformation problem is normally defined in terms of properties of simultaneous equations. ${ }^{1}$ I therefore begin by translating the classical concept of 'labour-value' into linear production theory (e.g., see Kurz and Salvadori 1995). The formality imparts precise semantics to our key concepts, which helps identify the conceptual mistake.

Assume $n \in \mathbb{Z}^{+}$sectors that specialize in the production of one commodity type. The technique is a non-negative $n \times n$ input-output matrix of inter-sector coefficients, $\mathbf{A}=\left[a_{i, j}\right]$. Each $a_{i, j} \geq 0$ is the quantity of commodity $i$ directly required to produce one unit of commodity $j$. Assume (i) A is fully connected, (ii) I - A is of full rank, and (iii) there exists

${ }^{1}$ For examples of alternative interpretations, see Elson 1979 and Fine and Saad-Filho 2004, 133. 


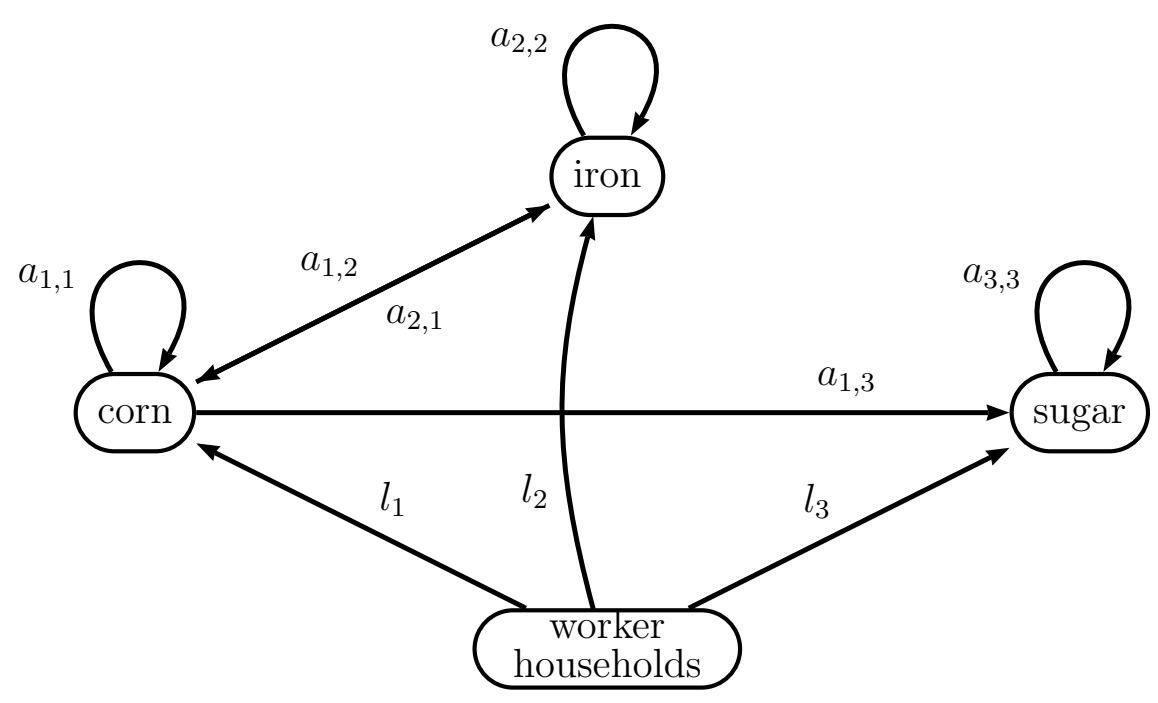

$$
\left[\begin{array}{c}
\mathbf{A} \\
\mathbf{l}
\end{array}\right]=\left[\begin{array}{ccc}
a_{1,1} & a_{1,2} & a_{1,3} \\
a_{2,1} & a_{2,2} & 0 \\
0 & 0 & a_{3,3} \\
l_{1} & l_{2} & l_{3}
\end{array}\right]
$$

Figure 1: A technique for an example 3-sector economy depicted as a directed graph and a matrix.

a vector $\mathbf{x}^{\mathrm{T}} \in \mathbb{R}_{+}^{n}$ such that $\mathbf{x}^{\mathrm{T}}>\mathbf{A} \mathbf{x}^{\mathrm{T}}$, i.e., the technique is productive. The elements of the $1 \times n$ vector, $\mathbf{l}=\left[l_{i}\right]$, are direct labour coefficients, where each $l_{i}>0$ is the quantity of labour directly required to output 1 unit of commodity $i$. Figure 1 depicts an example technique both as a matrix and weighted directed graph.

The total "coexisting labour" (see Hodgskin 1825; Marx 2000, chapter 21, section 3; Perelman 1987, chapter 5) supplied to reproduce commodity $i$ is the direct labour operating in sector $i$ plus the indirect labour operating in other sectors of the economy that is simultaneously supplied, in parallel, to replace all the commodity inputs used-up during the production of 1 unit of commodity $i$.

Commodities vary in their "difficulty of production" (e.g., Ricardo 2005 [1817], 106) because they require different quantities of coexisting labour for their reproduction. The classical labour theory of value is founded on this objective cost property of commodities, i.e., their labour-value.

To calculate a labour-value we vertically integrate over the technique (e.g., Pasinetti 1980). For example, production of unit $i$ uses-up direct labour $l_{i}$ plus the bundle of input commodities $\mathbf{A}^{(i)}$ (i.e., column $i$ of ma- 
trix A). This used-up input bundle is replaced by the simultaneous expenditure of indirect labour $\mathbf{1} \mathbf{A}^{(i)}$ operating in other sectors. But this production itself uses-up another bundle of input commodities $\mathbf{A A}{ }^{(i)}$, which is also replaced by the simultaneous expenditure of an additional amount of indirect labour $\mathbf{I A A} \mathbf{A}^{(i)}$. To count all the coexisting labour, $v_{i}$, we continue the sum; that is,

$$
\begin{aligned}
v_{i} & =l_{i}+\mathbf{l} \mathbf{A}^{(i)}+\mathbf{l} \mathbf{A} \mathbf{A}^{(i)}+\mathbf{l} \mathbf{A}^{2} \mathbf{A}^{(i)}+\ldots \\
& =l_{i}+\mathbf{l}\left(\mathbf{I}+\mathbf{A}+\mathbf{A}^{2}+\ldots\right) \mathbf{A}^{(i)} \\
& =l_{i}+\mathbf{l}\left(\sum_{n=0}^{\infty} \mathbf{A}^{n}\right) \mathbf{A}^{(i)}
\end{aligned}
$$

This infinite sum converges since the technique is productive (see Lancaster 1968, chapter 6). The vector of labour-values, from Equation (1), is then

$$
\mathbf{v}=\mathbf{l}+\mathbf{l}\left(\sum_{n=0}^{\infty} \mathbf{A}^{n}\right) \mathbf{A}=\mathbf{l} \sum_{n=0}^{\infty} \mathbf{A}^{n} .
$$

An alternative representation of the infinite series $\sum \mathrm{A}^{n}$ is the Leontief inverse $(\mathbf{I}-\mathbf{A})^{-1}$. Hence, $\mathbf{v}=\mathbf{l}(\mathbf{I}-\mathbf{A})^{-1}$; that is:

Definition 1. "Classical labour-values", v, are given by

$$
\mathbf{v}=\mathbf{v A}+\mathbf{l} .
$$

Now that we have defined labour-values, let us turn to two famous contradictions in the classical labour theory of value.

\section{RICARDO'S PROBLEM OF AN INVARIABLE MEASURE OF VALUE}

Consider a tree A that is twice the height of a tree $\mathrm{B}$. At a later date tree $\mathrm{A}$ is three times the height of tree $\mathrm{B}$. Assume we only know the relative change in heights. Does this change indicate that tree A has increased in size, tree B has decreased in size, or some combination of these causes? To answer this question we need an absolute measure of height that is invariable over time.

The metre is such an invariable standard. We measure the absolute height of tree A and B in metres, both before and after the change. Then we can unambiguously determine the cause of the variation in relative heights. 
The definition and adoption of the metre by the French state after the revolution in 1793 was accompanied by much theoretical debate and reflection (Roncaglia 2005, 192). Ricardo, a contemporary of these events, recognized that an objective theory of economic value requires an analogous invariable standard of measurement.

Market prices-whether stated in terms of exchange ratios between commodities or in terms of a money-commodity-cannot function as a standard because prices merely indicate relative values:

If for example a piece of cloth is now the value of 2 ounces of gold and was formerly the value of four I cannot positively say that the cloth is only half as valuable as before, because it is possible that the gold may be twice as valuable as before (Ricardo 2005a, 289).

The cause of an altered exchange ratio might be due to an alteration in the absolute value of the standard itself. Picking a market price to measure absolute value is analogous to picking the height of a specific tree to function as an invariable standard of length. Between measurements the chosen tree might grow (or get cut down in size).

Perhaps we should not try to find a standard? This is not an option because, lacking an invariable standard, the theory of value collapses into subjectivity, leaving "every one to chuse his own measure of value" (Ricardo 2005a, 370). In consequence, public statements about objective value, such as 'commodity A is now less valuable than one year ago', would, strictly speaking, be nonsense.

Ricardo states that if we had "possession of the knowledge of the law which regulates the exchangeable-value of commodities, we should be only one step from the discovery of the measure of absolute value" (Ricardo 2005b, 315). Ricardo therefore looks beyond exchange ratios in the marketplace to seek a regulating cause that might constitute a "standard in nature" (Ricardo 2005a, 381).

Ricardo defines "natural prices" as stable exchange ratios that are independent of "accidental and temporary deviations" (Ricardo 2005 [1817], 109) between supply and demand. Reproducible commodities are those "that may be multiplied [...] almost without any assignable limit, if we are disposed to bestow the labour necessary to obtain them" (Ricardo 2005 [1817], 59). Ricardo claims that the natural price of a reproducible commodity is regulated by its "difficulty of production" measured in labour time (e.g., Ricardo 2005 [1817], chapter 4). In conditions of constant 
"difficulty of production" market prices gravitate toward or around their natural prices due to profit-seeking behavior, which reallocates capital to high-profit sectors and away from low-profit sectors.

Such natural prices, or "prices of production" (Marx 1971 [1894], ch. 9), are equilibrium prices with uniform profit-rates,

$$
\mathbf{p}=(\mathbf{p A}+\mathbf{l} w)(1+r),
$$

where $\mathbf{p}$ is a vector of prices (measured, say, in pounds sterling), $w$ is a wage rate (pounds per hour), and $r$ is a uniform rate of profit or percentage interest-rate on the money invested to fund the period of production. Equation (3) states that the production price $p_{i}$ of commodity-type $i$ has three components: (i) the cost of the input bundle, $\mathbf{p} \mathbf{A}^{(i)}$, paid to other sectors of production, (ii) the wage costs, $l_{i} w$, paid to workers in sector $i$, and (iii) the profits, $\left(\mathbf{p A}^{(i)}+l_{i} w\right) r$, received by capitalists, as owners of firms in this sector, on the money-capital they advance to pay input and direct labour costs (collectively, the cost-price).

Now if "difficulty of production", measured in units of labour, in fact regulates natural prices then, in theory, we can measure (absolute) labourvalues to unambiguously determine the cause of variations in (relative) prices. We would have identified a "standard in nature" and Ricardo could "speak of the variation of other things, without embarrassing myself on every occasion with the consideration of the possible alteration in the value of the medium in which price and value are estimated" (Ricardo 2005 [1817], 80).

In fact, in some special cases labour-values do vary one-to-one with natural prices. For instance, Adam Smith (1994 [1776], 53) restricts the applicability of a labour theory of value to an "early and rude state of society" that precedes the "accumulation of stock", where profits are absent and "the whole produce of labour belongs to the labourer". In these circumstances a natural price is simply the wage bill of the total coexisting labour supplied to produce the commodity; that is,

Proposition 1. $r=0$ implies $\mathbf{p}=w \mathbf{v}$ (see appendix for proof).

So prices are proportional to labour-values with constant of proportionality $w$. Hence (relative) prices vary one-to-one with (absolute) labourvalues. 
But in general natural prices fail to vary one-to-one with labour-values. The reason is simple: production prices, $\mathbf{p}$, are a function of the profitrate, $r$, but labour-values, $\mathbf{v}$, are not. Hence a variation in the profitrate alters prices but leaves labour-values entirely unchanged. As Ricardo (2005a) clearly identifies: price depends on the distribution of income (i.e., how the net product is distributed in the form of wage and profit income) but "difficulty of production", a purely technical measure of direct and indirect labour costs, does not; therefore, production prices have an additional degree-of-freedom unrelated to labour-values. In general, the relative value of a commodity varies independently of its absolute value.

This is very perplexing since it is analogous to discovering that the relative size of two trees can change even though their absolute sizes, measured in metres, remain unaltered. Such a discovery would imply the metre is not an invariable standard of size, or one's theory of size is flawed. Ricardo's problem of an invariable standard of value arises, therefore, because his labour theory of value cannot fully account for production prices. The profit component of price appears to be unrelated to any objective labour cost. Although "the great cause of the variation of commodities is the greater or less quantity of labour that may be necessary to produce them" there is another "less powerful cause of their variation" (Ricardo 2005a, 404).

Ricardo understands the necessity for an invariable standard in his theoretical framework yet simultaneously understands the conditions that prevent this necessity from being met. Faced with a contradiction he is forced to draw the negative conclusion that there cannot be an invariable standard of value.

Now let us turn to a related problem in Marx's theory of value.

\section{MARX'S TRANSFORMATION PROBLEM}

Marx (1954 [1887]) explicitly assumes prices are proportional to labourvalues in Volume I of Capital. On this basis profit is the money representation of the unpaid or "surplus labour" of the working class. But Marx must establish the generality of this proposition in the case of (nonproportional) production prices. He tackles the issue in unfinished notes published as Volume III of Capital (Marx 1971 [1894]).

Marx proposes that aggregates of labour-values and production prices are proportional, even though individual prices and labour-values diverge, and therefore total profit remains the money representation of total surplus labour. 
Let us reproduce Marx's reasoning in terms of linear production theory. Define $\mathbf{q}=\left[q_{i}\right]$ as the scale of production or gross product and $\mathbf{w}=\left[w_{i}\right]$ as the real wage. The total labour supplied is therefore $\mathbf{l q}^{\mathrm{T}}$ and bundle $\overline{\mathbf{w}}=\left(1 / \mathbf{l q}^{\mathrm{T}}\right) \mathbf{w}$ is the real wage consumed per unit of labour supplied.

Marx defines the "surplus-labour" in sector $i$ as the labour supplied in excess of the labour-value of the real wage consumed, i.e., $l_{i} q_{i}-l_{i} q_{i} \mathbf{v} \overline{\mathbf{w}}^{\mathrm{T}}$. The "rate of surplus-value", or "degree of exploitation", for sector $i$, is then the ratio of surplus-labour to the labour-value of the real wage. Marx assumes, for simplicity, that the degree of exploitation is uniform across sectors,

$$
\theta=\frac{l_{i} q_{i}-l_{i} q_{i} \mathbf{v} \overline{\mathbf{w}}^{\mathrm{T}}}{l_{i} q_{i} \mathbf{v} \overline{\mathbf{w}}^{\mathrm{T}}}=\frac{1-\mathbf{v} \overline{\mathbf{w}}^{\mathrm{T}}}{\mathbf{\mathbf { v }} \overline{\mathbf{w}}^{\mathrm{T}}} .
$$

A high (resp. low) $\theta$ implies capitalists receive a larger (resp. smaller) share of the fruits of the labour they employ.

Now, according to Marx, only "living labour" creates profit from production. Hence the profit produced in each sector depends on the labour directly employed in that sector (the "variable capital") but is independent of the scale and composition of the material inputs to that sector (the "constant capital"). What, then, is the profit-rate in each sector?

Marx considers an initial situation of prices proportional to labourvalues. In these circumstances a sector's profit-rate is the ratio of surpluslabour to the sum of the labour-value of constant and variable capitals,

$$
r_{i}=\frac{\left(1-\mathbf{v} \overline{\mathbf{w}}^{\mathrm{T}}\right) l_{i} q_{i}}{\mathbf{v A}^{(i)} q_{i}+\mathbf{v} \overline{\mathbf{w}}^{\mathrm{T}} l_{i} q_{i}}=\theta \frac{1}{\left(\mathbf{v A} \mathbf{A}^{(i)} / \mathbf{v} \overline{\mathbf{w}}^{\mathrm{T}} l_{i}\right)+1} .
$$

In consequence, the profit-rates in each sector, $r_{i}$, are only equal if the "organic compositions" of capitals, that is the ratios $\mathbf{v A} \mathbf{A}^{(i)} / \mathbf{v} \overline{\mathbf{w}}^{\mathrm{T}} l_{i}$, are also all equal (Marx 1954 [1887], chapter 25, section 1). But they are not equal; hence, "in the different spheres of production with the same degree of exploitation, we find considerably different rates of profit corresponding to the different organic composition of these capitals" (Marx 1971 [1894], 155).

Marx notes that his initial situation is unstable: "The rates of profit prevailing in the various branches of production are originally very different" (Marx 1971 [1894], 158) but, during the formation of production prices, the different rates "are equalized by competition to a single general [uniform] rate of profit” (Marx 1971 [1894], 158). 
Marx proposes that production prices conservatively redistribute the surplus-labour amongst capitalist owners (in the form of commodities purchased with profit income), at which point,

although in selling their commodities the capitalists of various spheres of production recover the value of the capital consumed in their production, they do not secure the surplus-value [i.e., surplus-labour], and consequently the profit, created in their own sphere by the production of these commodities (Marx 1971 [1894], 158).

The capitalists share the available pool of surplus-labour in proportion to the size of the money-capitals they advance rather than the size of the (value-creating) workforces they employ.

Marx provides numerical examples to demonstrate the redistribution of surplus-value. He computes a uniform (labour-value) profit-rate, $r_{v}$, by dividing the aggregate surplus-labour by the aggregate labour-value of constant and variable capital,

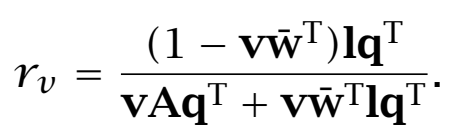

Marx states that the (labour-value) profit-rate, $r_{v}$, is identical to the uniform (money) profit-rate, $r$, which obtains once production prices have formed. He defines 'prices of production' as the initial cost-price of a commodity, which is proportional to labour-value, marked-up by the uniform profit-rate, $r_{v}$ (Marx 1971 [1894], 157). Let $\alpha$ be the constant of proportionality. Then we can write Marx's production prices as

$$
\mathbf{p}^{\star}=\alpha\left(\mathbf{v A}+\mathbf{l}\left(\mathbf{v} \overline{\mathbf{w}}^{\mathrm{T}}\right)\right)\left(1+r_{v}\right) .
$$

Marx’s production prices $\mathbf{p}^{\star}$ are not proportional to labour-values:

[O]ne portion of the commodities is sold above its [labour-]value in the same proportion in which the other is sold below it. And it is only the sale of the commodities at such prices that enables the rate of profit for capitals [to be uniform], regardless of their different organic composition (Marx 1971 [1894], 157).

In Marx's view production prices scramble and obscure the source of profit in surplus-labour. But the labour theory of value continues to hold in the aggregate because the "transformation" from unequal profit-rates 
to production prices is conservative. Nominal price changes neither create nor destroy surplus-labour, but merely redistribute it.

Marx therefore claims that three aggregate equalities are invariant over the transformation: (i) the (money) profit-rate, $r$, is equal to the (labour-value) profit-rate, $r_{v}$; (ii) "the sum of the profits in all spheres of production must equal the sum of the surplus-values", (Marx 1971 [1894], 173); and (iii) "the sum of the prices of production of the total social product equal the sum of its [labour-]value" (Marx 1971 [1894], 173) (here Marx assumes, for simplicity, that $\alpha=1$ ).

And in fact these equalities hold. Marx's 'prices of production' are computed from the assumption that money and labour-value profit-rates are equal and therefore equality (i) is true by definition. Also, Marx's prices $\mathbf{p}^{\star}$ satisfy equalities (ii) and (iii) (see Proposition 2 in the appendix). Hence, production-prices and labour-values, although non-proportional, are nonetheless one-to-one in the aggregate. Profit, despite appearances, is a money representation of surplus-labour.

But the first critic of the transformation is Marx himself. He immediately observes that "the cost-price of a commodity equalled the value of the commodities consumed in its production" (Marx 1971 [1894], 165). Marx's 'prices of production', defined by Equation (5), are calculated on the basis of untransformed cost-prices, $\alpha\left(\mathbf{v A}+\mathbf{l}\left(\mathbf{v} \overline{\mathbf{w}}^{\mathrm{T}}\right)\right)$, which are proportional to labour-value. But since this assumption is false "there is always the possibility of an error if the cost-price of a commodity in any particular sphere is identified with the [labour-]value of the means of production consumed by it" (Marx 1971 [1894], 165). As Marco Lippi $(1979,47)$ remarks, "the magnitudes on the basis of which surplus-value has been redistributed-that is, capital advanced, measured in [labour-]value-are not identical to the prices at which elements of capital are bought on the market. He therefore admits that the prices previously calculated must be adjusted". However, Marx does not pursue the adjustment but instead remarks that "our present analysis does not necessitate a closer examination of this point" (Marx 1971 [1894], 165).

Once we make this adjustment then production prices are not defined by Marx's Equation (5) but by Equation (3). And now Marx's aggregate equalities do not hold, except in certain special cases. The transformation problem is then the general impossibility of satisfying Marx's conservation conditions. In fact, we can deduce: 
Proposition 3. All Marx's equalities are true only if the economy satisfies the special condition, $\mathbf{v}\left(\mathbf{I}-\left(\mathbf{A}+\overline{\mathbf{w}}^{T} \mathbf{l}\right)(1+r)\right) \mathbf{q}^{T}=0$ (see appendix for proof).

Proposition 3 specifies a macroeconomic constraint between labourvalues, income distribution and the scale of production. Conditions that satisfy the constraint are zero profit, a uniform organic composition of capital, or a scale of production in certain special proportions (for further details see Abraham-Frois and Berrebi 1997, chapter 6). But, in general, there is no economic reason why this macroeconomic constraint should hold, especially as income distribution and the scale of production vary independently of labour-values. In consequence, a conservative transformation does not exist and "there is no rigorous quantitative connection between the labour time accounts arising from embodied labour coefficients and the phenomenal world of money price accounts" (Foley 2000, 17).

The transformation problem is the primary reason for the modern rejection of the logical possibility of a labour theory of value. The debate has generated a large literature spanning over one hundred years. Ian Steedman (1981) provides the definitive statement of the negative consequences for Marx's value theory. First, the theory is internally inconsistent because Marx "assumes that $\left[r_{v}\right]$ is the rate of profit but then derives the result that prices diverge from [labour-]values, which means precisely, in general, that $\left[r_{v}\right]$ is not the rate of profit" (Steedman 1981, 31). Second, the theory is redundant because "profits and prices cannot be derived from the ordinary [labour-]value schema, that $\left[r_{v}\right]$ is not the rate of profit and that total profit is not equal to surplus value" (Steedman 1981, 48). Steedman notes, following Paul Samuelson (1971), that given a technique and a real wage (the "physical schema") one can determine (a) profits and prices and (b) labour-values. But, in general, there is "no way" of relating (a) and (b).

Despite Marx's efforts it appears that a theory of value based exclusively on labour-cost cannot account for price phenomena or the substance of capitalist profit.

\section{TOTAL LABOUR COSTS}

Now that we have stated the classical problems we can turn to understanding why they exist. Clearly, prices and labour-values are incommensurate because a price depends on a profit-rate but a labour-value does 


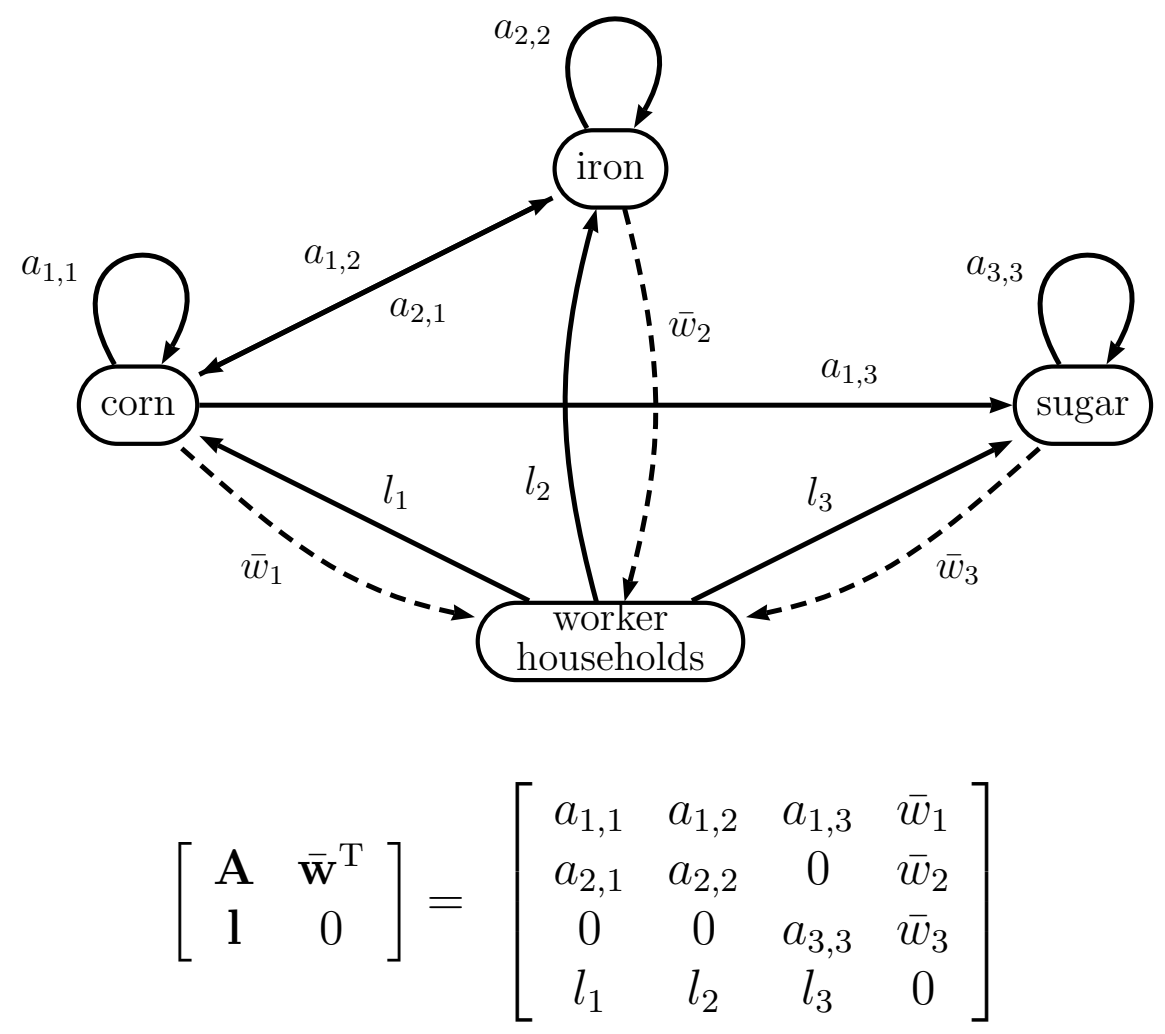

Figure 2: A social accounting matrix for an example 3-sector simple production economy depicted as a directed graph. This graph is identical to Figure 1 apart from the addition of worker consumption $\overline{\mathbf{w}}$.

not. But we need to dig deeper, and apply conceptual analysis to the concept 'labour-value', to discover the fundamental reason why money costs and labour costs diverge. First, I will examine two related properties of labour-values, in the context of an economy where capitalist profit is absent, which are subtle and normally overlooked.

\section{The independence of labour-values from the real wage}

Figure 2 depicts an example economy where all household income takes the form of wages (see Marx's concept of "simple production"). There is no government or financial sector. The social accounting matrix therefore simply specifies the technique and the real wage consumed per unit of labour supplied, $\overline{\mathbf{w}}$.

Earlier, I described the computation of a labour-value as a procedure of vertical integration. If we perform this procedure in the context of a social accounting matrix we immediately notice that some input paths are ignored. Specifically, the real wage inputs to worker households, drawn as dashed arcs in Figure 2, are not vertically integrated. So the labour 
supplied to produce the real wage, which maintains and reproduces the working class, is excluded as a component of the labour cost of commodity $i$. Why is this coexisting labour not counted?

A labour-value is the answer to the question: "What is the total coexisting labour supplied to reproduce 1 unit of a commodity?" But it is not the answer to the question: "What is the total coexisting labour supplied to reproduce 1 unit of a commodity and reproduce the labour that reproduced that unit?" Measuring the cost of reproducing the very resource that serves as the measure of cost would be like measuring the height of a tree with a metre rod and including the length of the rod as part of the tree's height.

We can look at this another way. Any system of measurement defines a standard unit (e.g., the metre). We do not ask: "How many metres are in one metre?" since the measure of the standard unit is by definition a unit of the standard. In a labour theory of value the question "What is the labour-value of one unit of direct labour?" is similarly ill-formed: the real cost of 1 hour of labour, measured by labour time, is 1 hour. No further reduction is possible or required. The self-identity of the measuring standard is a conceptual necessity in any system of measurement. So whether workers consume one bushel or a thousand bushels of corn to supply a unit of direct labour makes no difference to the labour-value of that unit of direct labour: an hour of labour-time is an hour of labour-time. In consequence, the procedure of vertical integration, when applied to a social accounting matrix, always terminates at labour inputs and does not further reduce labour inputs to the real wage.

\section{Labour-values as total labour costs}

Labour-values, as a conceptual necessity, exclude the reproduction costs of labour (i.e., the coexisting labour supplied to reproduce the real wage). In the context of a simple production economy the procedure of vertical integration therefore reduces all real costs (such as corn, iron and sugar) to quantities of direct labour except the cost of labour. Hence classical labour-values, in this context, are total labour costs:

Definition 2. A commodity's total labour cost is (i) a measure of the coexisting labour supplied to reproduce it that (ii) only excludes the reproduction cost of labour. 
The classical proposition that equilibrium prices of reproducible goods are proportional to labour-values in an "early and rude state" (Smith 1994 [1776]) is not controversial. Indeed, even critics of a labour theory of value accept this (e.g., Samuelson 1971; Steedman 1981; Roemer 1982). Natural prices are proportional to labour-values, that is $\mathbf{p}=w \mathbf{v}$ (see Proposition 1 ), because both accounting systems, that is money and labour costs, apply the same accounting convention: all commodities are reduced to a scalar measure of total cost-either total money or total labour cost. The accounting systems are dual or mutually consistent and therefore related by the price of labour, $w$.

Consequently, in a simple production economy the natural price of a commodity is the wage bill of the total coexisting labour supplied to produce it. Commodities that require more of society's labour-time to produce sell at higher prices in equilibrium.

Now let us introduce capitalist profit income and determine exactly why this simple relationship breaks down.

\section{CAPITALIST HOUSEHOLDS}

The natural prices of an economy with capitalist profit are production prices given by Equation (3) where the profit-rate is uniform across all sectors. In this situation capitalists supply money-capital to firms to meet production costs and receive profit income proportional to their advance. This profit mark-up, or price of money-capital, $r$, forms a cost component of the production price.

Assume firms do not self-finance. Then the vector of cost prices, or money-capital requirement coefficients, $\mathbf{m}=\left[m_{i}\right]$, where $m_{i}=\mathbf{p} \mathbf{A}^{(i)}+$ $l_{i} w$, denotes the quantity of money-capital supplied to produce unit outputs (see also Vickers 1987).

Figure 3 depicts a social accounting matrix for a capitalist economy in a state of "simple reproduction" (Marx 1954 [1887], chapter 23) where capitalists spend all their profit income on personal consumption and therefore no capital accumulation takes place. "Simple reproduction" is identical to "simple production" apart from the addition of a capitalist household sector that funds production by supplying money-capital. The social accounting matrix additionally specifies the distribution of the net product in the form of the real wage and capitalist consumption.

Money-capital is not money but loan capital, i.e., money advanced during the production period, from capitalists to firms, which earns a return. A quantity of money-capital therefore denotes a sum of loaned money 


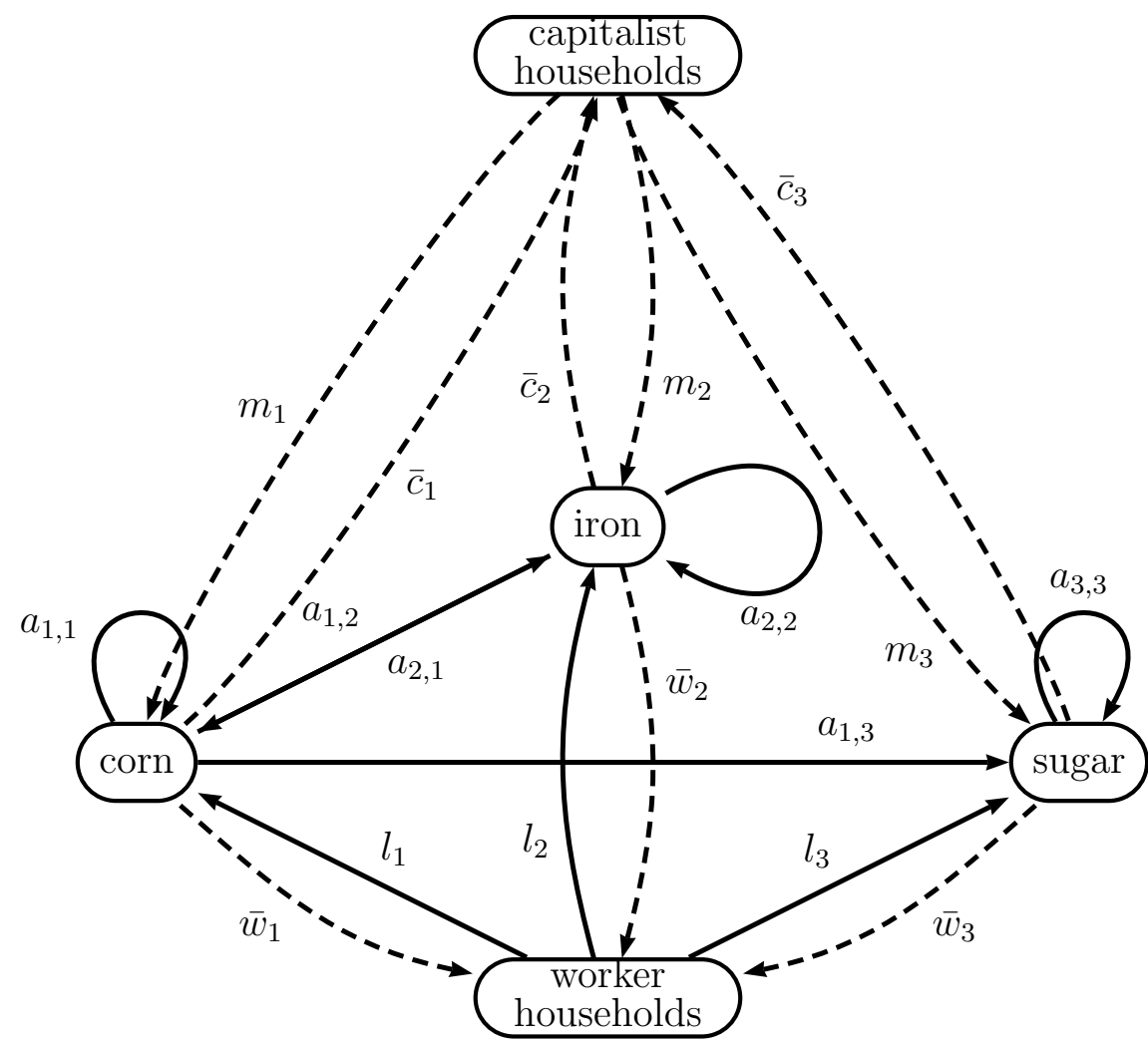

$$
\left[\begin{array}{ccc}
\mathbf{A} & \overline{\mathbf{w}}^{\mathrm{T}} & \overline{\mathbf{c}}^{\mathrm{T}} \\
\mathbf{l} & 0 & 0 \\
\mathbf{m} & 0 & 0
\end{array}\right]=\left[\begin{array}{ccccc}
a_{1,1} & a_{1,2} & a_{1,3} & \bar{w}_{1} & \bar{c}_{1} \\
a_{2,1} & a_{2,2} & 0 & \bar{w}_{2} & \bar{c}_{2} \\
0 & 0 & a_{3,3} & \bar{w}_{3} & \bar{c}_{3} \\
l_{1} & l_{2} & l_{3} & 0 & 0 \\
m_{1} & m_{2} & m_{3} & 0 & 0
\end{array}\right]
$$

Figure 3: A social accounting matrix for an example 3-sector capitalist economy depicted as a directed graph. This graph is identical to Figure 2 apart from the addition of a capitalist household sector.

(i.e., an outstanding principal) and the supply of money-capital denotes the supply of loan services, which includes loan management and actual transfers of money. The total supply of money-capital is $\mathbf{m q}^{\mathrm{T}}$. This quantity of loaned money is not identical to the total stock of money in circulation since "the same mass of actual money can [...] represent very different masses of money-capital" (Marx 1971 [1894], 510). In other words, a given stock of money may service multiple loans.

Capitalist households receive a bundle of consumption goods c. Figure 3 therefore also specifies capitalist consumption coefficients, $\overline{\mathbf{c}}=$ 
$\left(1 / \mathbf{m q}^{\mathrm{T}}\right) \mathbf{c}^{\mathrm{T}}$, which denote consumption per unit of money-capital supplied. For example, $\mathbf{c}=[10,5]$ indicates that capitalists consume 10 bushels of corn and 5 kilos of sugar per $£ 1$ of money-capital supplied to production, where $£ 1$ is the unit of account. These coefficients are analogous to worker consumption coefficients, $\overline{\mathbf{w}}=\left(1 / \mathbf{l q}^{\mathrm{T}}\right) \mathbf{w}$, which denote worker consumption per unit of labour supplied. The economy's net product is then $\mathbf{n}=\mathbf{w}+\mathbf{c}$.

Assume, for simplicity, that the supply of money-capital does not incur direct labour costs, such as the labour of managing and servicing loans. So money-capital is not produced, like a unit of corn, but merely advanced. (Including the direct labour cost of the supply of money-capital would add a new kind of labour activity to our model, and corresponding wage income, but would not remove the fundamental difference between profit and wages: profit is received in virtue of firm ownership, whereas the wage is received in virtue of labour supplied.)

\section{THE DIVERGENCE OF TECHNICAL AND TOTAL LABOUR COSTS}

Now that we have specified a social accounting matrix for an economy with capitalist profit we can reconsider the process of vertical integration.

Production now additionally requires the supply of money-capital $m_{i}$ (as shown by the dashed input edges from capitalist households to the system of production in Figure 3). Although the supply of money-capital, in this model, does not incur direct labour costs it does incur indirect labour costs. Capitalists do not advance money-capital for free, either nominally or in real terms. In parallel with the production of unit $i$, and the supply of money-capital $m_{i}$, capitalists consume commodity bundle $m_{i} \overline{\mathbf{c}}$. So, a quantity of coexisting labour, $m_{i} \mathbf{l} \overline{\mathbf{c}}^{\mathrm{T}}$, is indeed used-up during the supply of money-capital, specifically the coexisting labour that produces capitalist consumption goods.

The classical formula for labour-values-Equation (2)-ignores this coexisting labour because the supply of money-capital to production is not part of the technique, and therefore does not feature in the process of vertical integration (i.e., all the dashed input arcs from capitalist households in Figure 3 are not vertically integrated). Money-capital inputs are treated as an irreducible terminus on the same footing as the supply of labour. In consequence, classical labour-values do not count the labour supplied to produce capitalist consumption goods as a real cost of production.

Should this labour be counted as a cost? The classical theory excludes this labour without recognizing the existence of a theoretical choice. But 
the labour supplied to produce capitalist consumption goods is not a cost of reproducing labour and therefore necessarily excluded, as a conceptual necessity, from any definition of labour-value. The answer depends, quite simply, on what we want to measure. And what we want to measure depends on the theoretical questions we pose and seek to answer.

Classical labour-values, as purely technical measures of labour costs, answer questions about the productivity of labour over time independent of the distribution of income (see especially Flaschel 2010, part 1). The reciprocal of a classical labour-value measures the quantity of the commodity produced by a unit of coexisting labour, independent of the wider institutional context in which this activity occurs.

But if we want to measure total labour costs, that is measure the actual labour supplied to reproduce commodities in the complete circumstances in which production takes place, then we cannot use classical labourvalues. By definition total labour costs reduce all real costs to labour, except the cost of producing the real wage. But classical labour-values exclude the additional labour cost of producing capitalist consumption goods; hence, they do not measure total labour costs. This conclusion is simply a consequence of definitions.

In a monetary production economy, like capitalism, money-capital is not a technical input to production but nonetheless is an actual material prerequisite to production. In capitalist conditions a commodity cannot be produced without workers simultaneously performing tributary or "surplus" labour for a capitalist class. Classical labour-values, as a purely technical measure of labour cost, exclude this tributary labour as a real cost of production. A measure of total labour costs, by definition, must include it. Let us now do that.

\section{TOTAL LABOUR COSTS: NONSTANDARD LABOUR-VALUES}

Define the $n \times n$ matrix of capitalist consumption coefficients as

$$
\mathbf{C}=\overline{\mathbf{c}}^{\mathrm{T}} \mathbf{m}=\left[c_{i, j}\right],
$$

where each $c_{i, j}=\bar{c}_{i} m_{j}$ is the quantity of commodity $i$ capitalists consume per unit output of commodity $j$ (recall that $\bar{c}_{i}$ is the quantity of commodity $i$ consumed per unit of money-capital supplied and $m_{j}$ is the money-capital supplied per unit output of commodity $j$ ). Matrix $\mathbf{C}$, in consequence, is a capitalist consumption matrix that specifies how the production of output is synchronized with the distribution of goods from 
firms to capitalist households. It encapsulates the real costs of supplying money-capital to fund production in the different sectors of the economy.

Note that matrix $\mathbf{C}$ is a 'physical' input-output matrix that specifies relative material flows of commodities; for example, each element $c_{i, j}$ of $\mathrm{C}$ is measured in units identical to the corresponding element $a_{i, j}$ of the technique $\mathrm{A}$.

Define the technique augmented by capitalist consumption as

$$
\tilde{\mathbf{A}}=\mathbf{A}+\mathbf{C}=\left[\tilde{a}_{i, j}\right]
$$

where each $\tilde{a}_{i, j}=a_{i, j}+c_{i, j}$ is the quantity of commodity $i$, including that consumed by capitalists, directly used-up per unit output of $j$.

We now vertically integrate over the technique augmented by capitalist consumption: Production of commodity $i$ uses-up direct labour $l_{i}$ and the bundle of input commodities $\mathbf{A}^{(i)}+m_{i} \overline{\mathbf{c}}^{\mathrm{T}}=\mathbf{A}^{(i)}+\mathbf{C}^{(i)}$, consisting of means of production and capitalist consumption goods. This bundle is replaced by the simultaneous expenditure of labour $\mathbf{l}\left(\mathbf{A}^{(i)}+\mathbf{C}^{(i)}\right)$ operating in parallel, which itself uses-up input bundle $\tilde{\mathbf{A}}\left(\mathbf{A}^{(i)}+\mathbf{C}^{(i)}\right)$. To count all the coexisting labour we continue the sum; that is,

$$
\begin{aligned}
\tilde{v}_{i} & =l_{i}+\mathbf{l}\left(\mathbf{A}^{(i)}+\mathbf{C}^{(i)}\right)+\mathbf{l} \tilde{\mathbf{A}}\left(\mathbf{A}^{(i)}+\mathbf{C}^{(i)}\right)+\mathbf{l} \tilde{\mathbf{A}}^{2}\left(\mathbf{A}^{(i)}+\mathbf{C}^{(i)}\right)+\ldots \\
& =l_{i}+\mathbf{l}\left(\mathbf{I}+\tilde{\mathbf{A}}+\tilde{\mathbf{A}}^{2}+\ldots\right)\left(\mathbf{A}^{(i)}+\mathbf{C}^{(i)}\right) \\
& =l_{i}+\mathbf{l}\left(\sum_{n=0}^{\infty} \tilde{\mathbf{A}}^{n}\right)\left(\mathbf{A}^{(i)}+\mathbf{C}^{(i)}\right) .
\end{aligned}
$$

The vector $\tilde{\mathbf{v}}$ of total coexisting labour supplied to reproduce a unit bundle $\mathbf{u}=[1]$ of commodities is

$$
\tilde{\mathbf{v}}=\mathbf{l}+\mathbf{l}\left(\sum_{n=0}^{\infty} \tilde{\mathbf{A}}^{n}\right)(\mathbf{A}+\mathbf{C})=\mathbf{l} \sum_{n=0}^{\infty} \tilde{\mathbf{A}}^{n} .
$$

Rewrite the infinite series, such that $\tilde{\mathbf{v}}=\mathbf{l}(\mathbf{I}-\tilde{\mathbf{A}})^{-1}$; and therefore:

Definition 3. "Nonstandard labour-values", $\tilde{\mathbf{v}}$, are given by $\tilde{\mathbf{v}}=\tilde{\mathbf{v}} \tilde{\mathbf{A}}+\mathbf{l}$, where $\tilde{\mathbf{A}}=\mathbf{A}+\mathbf{C}$ is the technique augmented by capitalist consumption.

Nonstandard labour-values are a new measure of labour cost that are constructed by vertically integrating the real cost of capitalist consumption. They satisfy the definition of a total labour costs in the context of simple reproduction. 
Let us draw some contrasts between classical and nonstandard labourvalues. The classical formula, $\mathbf{v}=\mathbf{v A}+\mathbf{l}$, is a property of the technique and measures technical labour costs. In contrast, the nonstandard formula, $\tilde{\mathbf{v}}=\tilde{\mathbf{v}} \tilde{\mathbf{A}}+\mathbf{l}$, is a property of the social accounting matrix, including the distribution of real income, and measures total labour costs.

Classical labour-values are the sum of direct labour, $\mathbf{l}$, plus indirect labour, vA. Nonstandard labour-values are the sum of direct labour, $\mathbf{l}$, and indirect labour, $\tilde{\mathbf{v}} \mathbf{A}$, plus the "super-indirect" labour, $\tilde{\mathbf{v}}$, which is tributary labour devoted to the production of capitalist consumption goods. In general, $\tilde{\mathbf{v}}>\mathbf{v}$. But in the absence of 'profits on stock' nonstandard labour-values reduce to classical labour-values.

Classical labour-values view all household consumption (of workers and capitalists) as net output and therefore not a cost of production; in contrast, nonstandard labour-values view capitalist consumption as a real cost of production. Both schemes, of course, assign an ex post labour-value to capitalist consumption, since this bundle of goods requires labour resources to produce it. However, in the classical scheme, the direct labour supplied to produce capitalist consumption is surplus labour, i.e., supplied 'gratis', and therefore, by definition, does not constitute an ex ante cost of production (e.g., see Marx 1954 [1887], chapter 18; Marx 1971 [1894], part V, chapter 32).

The definition of nonstandard labour-values does not provide or rely upon any theory of income distribution or profit and is independent of the possible reasons why workers and capitalists consume specific consumption bundles. However, in order to calculate nonstandard labour-values the distribution of real income must be given, in much the same manner that, in order to calculate production prices, the distribution of nominal income must be given.

Both classical and nonstandard labour-values are functions of real or 'physical' data alone that may be operationalized without reference to monetary phenonema and constitute entirely self-consistent labour-cost accounting schemes. They measure different aspects of the same economy by applying different cost-accounting conventions to the analysis of the labour process. As we shall see, we need both measures to answer the full range of questions posed by a labour theory of value. 


\section{THE CATEGORY-MISTAKE: CONFLATING TECHNICAL AND TOTAL LABOUR COSTS}

Now that we have distinguished between technical and total labour costs we can understand the fundamental reason why money and labour costs diverge.

Money-capital has a price, the profit-rate, which is a 'mark up' component of the money cost of a commodity. Money-capital also has a real cost, which, in the case of simple reproduction, is capitalist consumption. Production prices, as total money costs, include the profit-rate as a money cost of production, and therefore prices depend on the distribution of nominal income. But classical labour-values, as technical labour costs, exclude the labour cost of money-capital as a real cost of production, and therefore labour-values are independent of the distribution of real income. In summary, the dual accounting systems apply different cost conventions. In consequence, there cannot be a one-to-one relationship between prices and labour-values: the profit-rate component of money costs refers to labour costs that are not counted.

The asymmetrical treatment of the commodity money-capital-present as a money cost in the price system but absent as a real cost in the labourvalue system -is the fundamental reason for the divergence of money and labour costs. A quantitative mismatch necessarily arises if total money costs are compared to partial labour costs.

The classical contradictions of the labour theory of value are the manifestation of the category-mistake of supposing that technical costs are of the same logical type as total costs. Hence Ricardo's search for an invariable measure and Marx's transformation are theoretical attempts to find Ryle's "elusive and insubstantial man" or "ghost".

The classical category-mistake has been, and continues to be, the major obstacle toward a deeper understanding of the relationship between social labour and monetary phenomena. For example, it has directed theoretical attention toward the contradictions and away from the existence of a simple one-to-one quantitative relation between production prices and labour costs.

Definition 4. A "steady-state economy" produces quantities, $\mathbf{q}=\mathbf{q A}{ }^{T}+\mathbf{w}+$ $\mathbf{c}$, at prices, $\mathbf{p}=(\mathbf{p A}+\mathbf{l} w)(1+r)$, where workers and capitalists spend what they earn, $\mathbf{p w}^{T}=\mathbf{l} \mathbf{q}^{T} w$ and $\mathbf{p} \mathbf{c}^{T}=(\mathbf{p A}+\mathbf{l} w) \mathbf{q}^{T} r$. 
Theorem 1. The production-prices of a steady-state economy are proportional to nonstandard labour-values, $\mathbf{p}=\tilde{\mathbf{v}} w$ (see appendix for proof).

In consequence, in a steady-state economy, the production-price of a commodity is the wage bill of the total coexisting labour supplied to reproduce it. Commodities that require more labour time to produce sell at proportionally higher prices in equilibrium. Natural prices-whether in an "early and rude state" or in our late and civilized times-vary one-toone with total labour costs.

How general is this proposition? The definition of total labour cost applies to any social accounting matrix. Hence, in more complex models, total labour costs include additional real costs of production, over and above capitalist consumption. For example, total labour-values, in circumstances of expanded reproduction with proportionate or non proportionate growth, are "vertically super-integrated labour coefficients", which additionally include the labour cost of supplying the net investment goods required to expand the scale of production. The natural prices in growing economies are therefore also proportional to total labour costs (see Wright 2013).

Many possible generalizations remain unexplored, however. For example, the robustness of such equivalence theorems have yet to be tested in the context of (i) more complex social accounting matrices, which include capitalist savings, a public sector, credit money etc., (ii) production with fixed capital, (iii) systems of joint production, and (iv) dynamic models of classical macrodynamics with gravitation of market prices to natural prices.

Now that we have identified the category-mistake, and introduced a distinction between classical and total labour costs, we can finally dissolve the classical problems.

\section{DISSOLUTION OF THE PROBLEM OF AN INVARIABLE MEASURE OF VALUE}

Ricardo conflates two concepts of difficulty of production that we can now distinguish. Classical labour-values, $\mathbf{v}$, measure 'difficulty of production' independent of an economy's institutional structure and distributive rules. A classical labour-value, $v_{i}$, is therefore a counterfactual measure of the total coexisting labour that would be supplied to reproduce commodity-type $i$ if workers did not perform tributary labour during the production of commodities. 
Nonstandard labour-values, $\tilde{\mathbf{v}}$, measure "difficulty of production" dependent on an economy's institutional structure and distributive rules. A nonstandard labour-value, $\tilde{v}_{i}$, is therefore an actual measure of the total coexisting labour supplied to reproduce commodity-type $i$ given that workers perform additional tributary labour during the production of commodities.

Ricardo wished to reduce the structure of natural prices (relative value) to "difficulty of production" (absolute value) measured in terms of some real cost basis, such as labour costs. Classical labour-values are an invariable measure of absolute value independent of the distribution of income and therefore we can use them to say, without 'embarrassment' or equivocation, that 'commodity A is now less valuable than one year ago' in the strictly technical sense that commodity A requires less labour resources to reproduce than it once did. But it is a category-mistake to hope or expect, as Ricardo did, that this standard can also explain the structure of natural prices.

Nonstandard labour-values, in contrast, explain the structure of natural prices in terms of objective quantities of coexisting labour supplied to produce commodities (Theorem 1). Hence they provide that all-important one-to-one relation, required by a labour theory of value, between absolute values, measured in terms of labour time, and relative prices.

The point is the following: classical labour-values answer distributionindependent questions about the technical difficulty of production of commodities, whereas nonstandard labour-values can answer distributiondependent questions about the actual difficulty of production of commodities. In consequence-and on condition we apply the appropriate concept of 'difficulty of production' in each case-we can justifiably make public statements about changes in objective value, independent of the distribution of income and simultaneously claim that relative values covary with absolute values, and thereby explain the structure of natural prices in terms of labour costs. Ricardo's belief in another "less powerful cause" of the variation of relative values, other than labour costs, is caused by the category-mistake. Ricardo's problem therefore dissolves.

\section{DISSOLUTION OF THE TRANSFORMATION PROBLEM}

Marx employs classical labour-values to address issues in the theory of exploitation (e.g., how many hours do workers supply in excess of the time required to produce their real wage?) and, in addition, issues in the theory of economic value (e.g., what does the nominal unit of account, 
such as $£ 1$, 'express' or measure?, what is the 'substance' of profit?, etc.) The distinction between classical and total labour-values permits us to separate these concerns and therefore avoid the transformation problem while preserving Marx's analysis of the capitalist labour process.

Let $\mathbf{n}=\mathbf{w}+\mathbf{c}$ be the net product of the economy, where $\mathbf{c}$ is the consumption bundle of capitalists. The total working day equals the classical labour-value of the net product, $\mathbf{l q}^{\mathrm{T}}=\mathbf{v n}^{\mathrm{T}}$ (see Proposition 4 in the appendix). Marx splits the working day into necessary labour, $\mathbf{v w}^{\mathrm{T}}$, which is the part 'technically necessary' to reproduce workers, and surplus labour, $\mathbf{v n}^{\mathrm{T}}-\mathbf{v} \mathbf{w}^{\mathrm{T}}\left(=\mathbf{v} \mathbf{c}^{\mathrm{T}}\right)$, which is an additional part appropriated by capitalists. Marx's normative point, among other things, is that production could occur without the performance of this surplus labour, and yet workers could continue to consume the same real wage.

Nonstandard labour-values, by definition, include surplus labour as a cost of production. In consequence, they do not split the working day into necessary and surplus parts. In terms of total labour costs the whole working day, $\mathbf{l} \mathbf{q}^{\mathrm{T}}=\tilde{\mathbf{v}} \mathbf{w}^{\mathrm{T}}$ (see Proposition 5 in the appendix), is 'socially necessary' to reproduce workers given that the real wage cannot be produced without the simultaneous performance of surplus labour for capitalists.

We can therefore restate Marx's concept of surplus labour in terms of nonstandard and classical labour-values. Surplus labour is the difference between (i) the labour time socially necessary and (ii) the labour time technically necessary to reproduce workers, i.e., $\tilde{\mathbf{v}}^{\mathrm{T}}-\mathbf{v} \mathbf{w}^{\mathrm{T}}$ (since $\left.\tilde{\mathbf{v}} \mathbf{w}^{\mathrm{T}}=\mathbf{l} \mathbf{q}^{\mathrm{T}}=\mathbf{v n}^{\mathrm{T}}\right)$.

Splitting the working day this way is both logical and illuminating, regardless of any relationship it may have to the price system, since it provides the quantitative basis for a normative critique of capitalist production. But it is a category-mistake to hope or expect, as Marx did, that a technical, and therefore partial, measure of surplus labour has a one-toone relation with a total measure of money profit. Money profit, in fact, has a one-to-one relation with total surplus labour, $\tilde{\mathbf{v}} \mathbf{n}^{\mathrm{T}}-\tilde{\mathbf{v}} \mathbf{w}^{\mathrm{T}}$, not Marx's surplus labour, $\mathbf{v n}^{\mathrm{T}}-\mathbf{v w}^{\mathrm{T}}$ (see Proposition 6 in the appendix).

In the context of the transformation problem, the Marxist tradition in general has accepted divergence of production prices from labour-values but defended conservation of labour-value in price, whereas critics have also accepted divergence but denied conservation of labour-value in price. But both sides of the argument are mistaken: once we measure in terms 
of total labour costs there is no divergence and there is aggregate conservation. Production prices represent total labour costs, i.e., nonstandard labour-values, and therefore capitalist profit is a money representation of labour time.

Corollary 1. All Marx's equalities obtain when labour-values measure total labour costs, specifically (i) the profit-rate equals the labour-value profitrate, (ii) total profit is proportional to surplus labour, and (iii) total production price is proportional to total labour-value (see appendix for proof).

In consequence, the standard criticisms of the classical labour theory of value do not apply: nonstandard labour-values are not internally inconsistent, since the money profit-rate equals the labour-value profit-rate, nor redundant, since production prices can be derived from labour-values by scaling by the money wage $w$. Hence a theory of value based exclusively on labour cost can account for price phenomena: total labour costs and prices are "two sides of the same coin". The transformation problem therefore dissolves.

This conclusion, it should be emphasized, destroys the basis of any claim that a labour theory of value is logically incoherent because prices and labour-values are quantitatively incommensurable in linear production models (e.g., Samuelson 1971; Lippi 1979; Steedman 1981).

\section{CONCLUSION}

The classical labour theory of value commits the category-mistake of supposing that classical labour-values, which measure strictly technical or material costs of production, are of the same logical type as natural prices, which measure non-technical or social costs of production, and therefore labour-values and prices, under appropriate equilibrium conditions, are mutually consistent. This category-mistake is the cause of Ricardo's problem of an invariable measure of value and Marx's transformation problem.

This essay has drawn a new distinction, lacking in the classical theory, between a technical and a total measure of labour cost, where a total labour cost includes additional real costs incurred in virtue of nontechnical conditions, such as production financed by money-capital. Classical labour-values, in this more refined conceptual framework, apply to distribution-independent questions about an economy, such as the productivity of labour or measuring the surplus-labour supplied by workers; whereas total labour-values apply to distribution-dependent questions, 
such as the relationship between nominal prices and the actual labour time required to produce commodities (i.e., issues in the theory of economic value). The classical problems dissolve by generalizing the classical labour theory to apply both concepts in the appropriate contexts.

The category-mistake has misdirected theoretical attention toward the contradictions and away from the fact that a commodity's natural price is the wage bill of the total coexisting labour supplied to produce it (Theorem 1). By ridding ourselves of longstanding conceptual confusions we discover the logical possibility of a new theoretical object: a more general labour theory of value with an invariable measure of value and without a transformation problem.

\section{APPENDIX}

Proposition 1. $r=0$ implies $\mathbf{p}=w \mathbf{v}$.

Proof. Set $r=0$ into price Equation (3) to get $\mathbf{p}=\mathbf{p A}+\mathbf{l} w$ or $\mathbf{p}=w \mathbf{l}(\mathbf{I}-\mathbf{A})^{-1}$. Since $\mathbf{v}=\mathbf{l}(\mathbf{I}-\mathbf{A})^{-1}$ the conclusion follows.

Proposition 2. Marx's 'production prices', $\mathbf{p}^{\star}$, satisfy (ii) the sum of profits is proportional to surplus labour, $\alpha\left(\mathbf{v A}+\mathbf{l}\left(\mathbf{v} \overline{\mathbf{w}}^{T}\right)\right) \mathbf{q}^{T} r \propto \mathbf{l q}^{T}-\mathbf{v} \mathbf{w}^{T}$, and (iii) the price of the gross product is proportional to its labour-value, $\mathbf{p}^{\star} \mathbf{q}^{T} \propto \mathbf{v q}^{T}$.

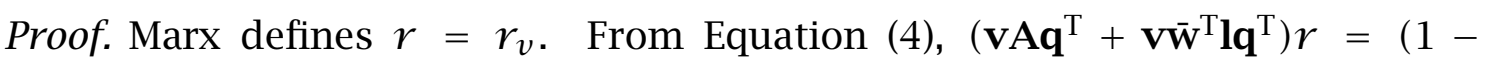
$\left.\mathbf{v} \overline{\mathbf{w}}^{\mathrm{T}}\right) \mathbf{l q}^{\mathrm{T}}=\mathbf{l q}^{\mathrm{T}}-\mathbf{v} \mathbf{w}^{\mathrm{T}}$ (since $\left.\overline{\mathbf{w}}=\left(1 / \mathbf{l q}^{\mathrm{T}}\right) \mathbf{w}\right)$, which establishes (ii). Multiply

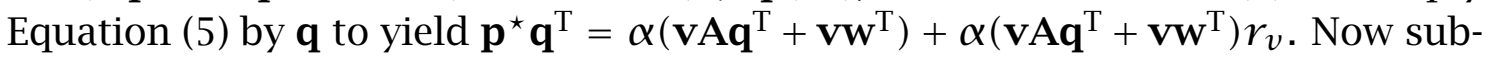
stitute for $r_{v}, \mathbf{p}^{\star} \mathbf{q}^{\mathrm{T}}=\alpha\left(\mathbf{v} \mathbf{A} \mathbf{q}^{\mathrm{T}}+\mathbf{v} \mathbf{w}^{\mathrm{T}}\right)+\alpha\left(\mathbf{l} \mathbf{q}^{\mathrm{T}}-\mathbf{v} \mathbf{w}^{\mathrm{T}}\right)=\alpha\left(\mathbf{v} \mathbf{A} \mathbf{q}^{\mathrm{T}}+\mathbf{l} \mathbf{q}^{\mathrm{T}}\right)$. Multiply Equation (2) by $\mathbf{q}$ and substitute $\mathbf{v} \mathbf{A} \mathbf{q}^{\mathrm{T}}+\mathbf{l} \mathbf{q}^{\mathrm{T}}=\mathbf{v} \mathbf{q}^{\mathrm{T}}$. Hence $\mathbf{p}^{\star} \mathbf{q}^{\mathrm{T}}=\alpha \mathbf{v} \mathbf{q}^{\mathrm{T}}$, which establishes (iii).

Proposition 3. All Marx's equalities are true only if the economy satisfies the special condition, $\mathbf{v}\left(\mathbf{I}-\left(\mathbf{A}+\overline{\mathbf{w}}^{T} \mathbf{l}\right)(1+r)\right) \mathbf{q}^{T}=0$.

Proof. (i) If total profit is proportional to total surplus-labour then

$$
(\mathbf{p A}+\mathbf{l} w) \mathbf{q}^{\mathrm{T}} r=\alpha\left(1-\mathbf{v} \overline{\mathbf{w}}^{\mathrm{T}}\right) \mathbf{l} \mathbf{q}^{\mathrm{T}},
$$

where $\alpha$ is the constant of proportionality. (ii) If the profit-rate equals the labour-value profit-rate substitute $r$ from (4) to get

$$
(\mathbf{p A}+\mathbf{l} w) \mathbf{q}^{\mathrm{T}}=\alpha\left(\mathbf{v A q ^ { \mathrm { T } }}+\mathbf{v} \overline{\mathbf{w}}^{\mathrm{T}} \mathbf{l} \mathbf{q}^{\mathrm{T}}\right) .
$$

(iii) If the total price of the gross product is proportional to its labour-value then $\mathbf{p q}^{\mathrm{T}}=\alpha \mathbf{v} \mathbf{q}^{\mathrm{T}}$. Price Equation (3) implies that

$$
(\mathbf{p A}+\mathbf{l} w) \mathbf{q}^{\mathrm{T}}(1+r)=\alpha \mathbf{v} \mathbf{q}^{\mathrm{T}} .
$$


Substitute (8) into (7) to get $\mathbf{v q} \mathbf{q}^{\mathrm{T}}=\left(\mathbf{v A \mathbf { q } ^ { \mathrm { T } }}+\mathbf{v} \overline{\mathbf{w}}^{\mathrm{T}} \mathbf{l} \mathbf{q}^{\mathrm{T}}\right)(1+r)$, which can be rearranged into the form

$$
\mathbf{V}\left(\mathbf{I}-\left(\mathbf{A}+\overline{\mathbf{w}}^{\mathrm{T}} \mathbf{l}\right)(1+r)\right) \mathbf{q}^{\mathrm{T}}=0 .
$$

Hence Marx's equalities (i), (ii) and (iii), with a given constant of proportionality $\alpha$, imply (9).

Theorem 1. The production-prices of a steady-state economy are proportional to nonstandard labour-values, $\mathbf{p}=\tilde{\mathbf{v}} w$.

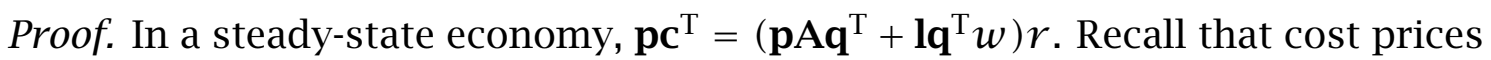
$\mathbf{m}=\mathbf{p A}+\mathbf{l} w$. Hence $r=\mathbf{p c}^{\mathrm{T}} / \mathbf{m} \mathbf{q}^{\mathrm{T}}=\mathbf{p} \overline{\mathbf{c}}^{\mathrm{T}}$. Substitute $r=\mathbf{p} \overline{\mathbf{c}}^{\mathrm{T}}$ into price Equation (3) to get $\mathbf{p}=(\mathbf{p A}+\mathbf{l} w)+(\mathbf{p A}+\mathbf{l} w) \mathbf{p} \overline{\mathbf{c}}^{\mathrm{T}}=(\mathbf{p A}+\mathbf{l} w)+\mathbf{m} \mathbf{p} \overline{\mathbf{c}}^{\mathrm{T}}=$ $\mathbf{p A}+\mathbf{p} \overline{\mathbf{c}}^{\mathrm{T}} \mathbf{m}+\mathbf{l} w=\mathbf{p}\left(\mathbf{A}+\overline{\mathbf{c}}^{\mathrm{T}} \mathbf{m}\right)+\mathbf{l} w=\mathbf{p} \tilde{\mathbf{A}}+\mathbf{l} w$. Hence $\mathbf{p}=\mathbf{l}(\mathbf{I}-\tilde{\mathbf{A}})^{-1} w=\tilde{\mathbf{v}} w$, by Definition 3.

Corollary 1. All Marx's equalities obtain when labour-values measure total labour costs, specifically (i) the profit-rate equals the labour-value profit-rate, (ii) total profit is proportional to surplus labour, and (iii) total production price is proportional to total labour-value.

Proof. This is a trivial consequence of Theorem 1, i.e., the proportionality of production prices and total labour costs.

Proposition 4. The total labour supplied equals the classical labour-value of the net product, $\mathbf{l} \mathbf{q}^{T}=\mathbf{v n}^{T}$.

Proof. Since $\mathbf{q}=\mathbf{q A} A^{\mathrm{T}}+\mathbf{n}^{\mathrm{T}}$ it follows that

$$
\mathbf{v}(\mathbf{I}-\mathbf{A}) \mathbf{q}^{\mathrm{T}}=\mathbf{v} \mathbf{n}^{\mathrm{T}} .
$$

But $\mathbf{v}=\mathbf{l}(\mathbf{I}-\mathbf{A})^{-1}$. Replace $\mathbf{v}$ on the LHS of (10) to get $\mathbf{l} \mathbf{q}^{\mathrm{T}}=\mathbf{v} \mathbf{n}^{\mathrm{T}}$.

Proposition 5. The total labour supplied equals the nonstandard labour-value of the real wage, $\mathbf{l q}^{T}=\tilde{\mathbf{v}} \mathbf{w}^{T}$.

Proof. In a steady-state economy, $\mathbf{l q}^{\mathrm{T}} w=\mathbf{p w}^{\mathrm{T}}$. Use Theorem 1 to substitute for p and the conclusion follows.

Proposition 6. Money profit, $(\mathbf{p A}+\mathbf{l} w) \mathbf{q}^{T} r$, is proportional to total surplus labour, $\tilde{\mathbf{v}} \mathbf{n}^{T}-\tilde{\mathbf{v}} \mathbf{w}^{T}$.

Proof. In a steady-state economy, $\mathbf{p c}^{\mathrm{T}}=(\mathbf{p A}+\mathbf{l} w) \mathbf{q}^{\mathrm{T}} r$. Hence we need to demonstrate $\mathbf{p} \mathbf{c}^{\mathrm{T}} \propto \tilde{\mathbf{v}} \mathbf{n}^{\mathrm{T}}-\tilde{\mathbf{v}} \mathbf{w}^{\mathrm{T}}$. Theorem 1 implies $\mathbf{p} \mathbf{c}^{\mathrm{T}}=\tilde{\mathbf{v}} \mathbf{c}^{\mathrm{T}} \boldsymbol{w}$. And $\tilde{\mathbf{v}} \mathbf{c}^{\mathrm{T}} \boldsymbol{w}=$ $\left(\tilde{\mathbf{v}} \mathbf{n}^{\mathrm{T}}-\tilde{\mathbf{v}} \mathbf{w}^{\mathrm{T}}\right) w$ by the definition of $\mathbf{n}$. 


\section{REFERENCES}

Abraham-Frois, Gilbert, and Edmond Berrebi. 1997. Prices, profits and rhythms of accumulation. Cambridge: Cambridge University Press.

Elson, Diane. 1979. The value theory of labour. In Value: the representation of labour in capitalism, ed. Diane Elson, London: CSE Books, 115-180.

Fine, Ben, and Alfredo Saad-Filho. 2004. Marx's Capital. London: Pluto Press, 4 edition.

Flaschel, Peter. 2010. Topics in classical micro- and macroeconomics: elements of a critique of Neoricardian theory. New York: Springer.

Foley, Duncan K. 2000. Recent developments in the labor theory of value. Review of Radical Political Economics, 32 (1): 1-39.

Hodgskin, Thomas. 1825. Labour defended against the claims of capital: or, The unproductiveness of capital proved with reference to the present combinations amongst journeymen. London: B. Steil.

Howard, Michael C., and John E. King. 1989. A history of Marxian economics, volume I, 1883-1929. London: Macmillan.

Howard, Michael C., and John E. King. 1992. A history of Marxian economics, volume II, 1929-1990. London: Macmillan.

Kurz, Heinz D., and Neri Salvadori. 1995. Theory of production: a long period analysis. Cambridge: Cambridge University Press.

Lancaster, Kelvin. 1968. Mathematical economics. New York: Dover Publications.

Lippi, Marco. 1979. Value and naturalism. London: New Left Books.

Marx, Karl. 1954 [1887]. Capital, volume 1. Moscow: Progress Publishers.

Marx, Karl. 1971 [1894]. Capital, volume 3. Moscow: Progress Publishers.

Marx, Karl. 2000. Theories of surplus Value. New York: Prometheus Books.

Pasinetti, Luigi L. 1980. The notion of vertical integration in economic analysis. In Essays on the theory of joint production, ed. Luigi L. Pasinetti, New York: Cambridge University Press, 16-43.

Passmore, John. 1978. A hundred years of philosophy. London: Penguin Books.

Perelman, Michael. 1987. Marx's crises theory: scarcity, labor and finance. Westport (CT): Praeger Publishers.

Ricardo, David. 2005a. Absolute value and exchangeable value. In The works and correspondence of David Ricardo, vol. IV, eds. Piero Sraffa and Maurice H. Dobb, Indianapolis: Liberty Fund.

Ricardo, David. 2005b. Ricardo to Trower, August 31, 1823. In The works and correspondence of David Ricardo, Vol. IX, eds. Piero Sraffa and Maurice H. Dobb, Indianapolis: Liberty Fund.

Ricardo, David. 2005 [1817]. Principles of political economy and taxation. In The works and correspondence of David Ricardo, vol. 1, eds. Piero Sraffa and Maurice H. Dobb, Indianapolis: Liberty Fund.

Roemer, John E. 1982. A general theory of exploitation and class. Cambridge, Massachusetts: Harvard University Press.

Roncaglia, Alessandro. 2005. The wealth of ideas: a history of economic thought. The Edinburgh Building, Cambridge: Cambridge University Press.

Ryle, Gilbert. 1984 [1949]. The concept of mind. Chicago: University of Chicago Press.

Samuelson, Paul A. 1971. Understanding the Marxian notion of exploitation: a summary of the so-called transformation problem between Marxian values and com- 
petitive prices. Journal of Economic Literature, 9 (2): 399-431.

Seton, Francis. 1957. The 'transformation problem'. Review of Economic Studies, 24: 149-160.

Sloman, Aaron. 1978. The computer revolution in philosophy: philosophy, science and models of mind. Sussex: Harvester Press and Humanities Press.

Smith, Adam. 1994 [1776]. The wealth of nations. New York: The Modern Library.

Steedman, Ian. 1981. Marx after Sraffa. London: Verso.

Vickers, Douglas. 1987. Money capital in the theory of the firm: a preliminary analysis. Cambridge: University of Cambridge.

von Bortkiewicz, Ladislaus. 1975 [1907]. On the correction of Marx's fundamental theoretical construction in the third volume of Capital. In Karl Marx and the close of his system, ed. Paul M. Sweezy, New York: Augustus M. Kelley, 199-221 (appendix).

Wittgenstein, Ludwig. 1953. Philosophical investigations. Oxford: Blackwell.

Wright, Ian. 2013. Pasinetti's hyper-integrated labor coefficients and the 'pure labor theory of value'. http://ssrn.com/abstract=2255732 (accessed April 23, 2013).

Ian Wright is a $\mathrm{PhD}$ candidate in the Department of Economics at the Open University, UK. His main research interests are theories of economic value, classical macrodynamics and agent-based macroeconomics.

Contact e-mail: <wrighti@acm.org> 